\title{
Talimogene laherparepvec and novel injectable oncolytic viruses in the management of metastatic melanoma
}

\author{
Frances G. Jenkins ${ }^{1}$, Jeffrey E. Johnson ${ }^{2}$, Frances Collichio ${ }^{3}$, David W. Ollila ${ }^{2}$ \\ ${ }^{1}$ School of Medicine, University of North Carolina at Chapel Hill, NC 27599, USA. \\ ${ }^{2}$ Department of Surgery, University of North Carolina at Chapel Hill, NC 27599, USA \\ ${ }^{3}$ Department of Medicine, Division of Oncology, University of North Carolina at Chapel Hill, NC 27599, USA.
}

Correspondence to: Prof. David W. Ollila, Department of Surgery, University of North Carolina at Chapel Hill, Chapel Hill, NC 27599, USA.E-mail: david_ollila@med.unc.edu

How to cite this article: Jenkins FG, Johnson JE, Collichio F, Ollila DW. Talimogene laherparepvec and novel injectable oncolytic viruses in the management of metastatic melanoma. J Trans/ Genet Genom 2021;5:396-413.

https://dx.doi.org/10.20517/jtgg.2021.29

Received: 5 Jun 2021 First Decision: 5 Jul 2021 Revised: 21 Jul 2021 Accepted: 3 Aug 2021 First online: 5 Nov 2021

Academic Editor: Sanjay Gupta Copy Editor: Yue-Yue Zhang Production Editor: Yue-Yue Zhang

\begin{abstract}
Talimogene laherparepvec (T-VEC) is an oncolytic virus (OV) therapy derived from the JS1 strain of herpes simplex virus one that was approved by the Food and Drug Administration in 2015 to be administered as direct injection therapy for patients with melanoma. The anti-tumor effects of T-VEC are due to viral-mediated tumor cell lysis at the site of administration and a local, and in some cases systemic, anti-tumor response via T cell-mediated host immune response pathways aided by GM-CSF. T-VEC has shown promising results for metastatic melanoma, particularly in patients with skin, lymph node, and soft tissue metastases (stages IIIB, IIIC, and IVa). Studies have explored the utility of T-VEC as monotherapy, neoadjuvant therapy, and in combination with other immunotherapies and targeted therapies. T-VEC has proven to improve durable response rates and overall survival with a very tolerable safety profile. More research is needed to better understand which patients are most likely to benefit from T-VEC therapy, which combination therapies are most effective, and how to sequence multimodality therapy. Additionally, new OVs are currently in development and/or being studied in clinical trials. In this review, we will discuss T-VEC as a monotherapy, neoadjuvant therapy, and combination therapy, in addition to future directions for melanoma therapy as it pertains to new OVs.
\end{abstract}


Keywords: Talimogene laherparepvec, melanoma, immunotherapy, intralesional therapy, oncolytic virus, neoadjuvant therapy

\section{INTRODUCTION}

Although the incidence rates of melanoma have climbed in recent years, the mortality rate has declined, a change likely attributable to the development and approval of various novel therapies for patients with advanced-stage melanoma ${ }^{[1]}$. Since 2011, the United States Food and Drug Administration (FDA) has approved the use of 10 new treatments (oral, infusional, and injectable) for metastatic melanoma ${ }^{[2]}$. Before the development of these efficacious therapies, the management of advanced locoregional melanoma was limited to surgical resection, radiation, isolated limb infusion, or perfusion, and marginally beneficial systemic options for distant disease ${ }^{[1,3,4]}$. Prior to 2011, the overall survival (OS) of patients with unresectable melanoma was 22-24 months for patients with disease involving the skin and lymph nodes (stage IIIB/CIVM1a), or 5-11 months patients with disease involving distant organs (stage IVM1b/c) ${ }^{[5]}$. For patients with distant metastatic disease, the most recent 5-year survival data from the Surveillance, Epidemiology, and End Results database in 2013 was $29.3 \%$, nearly double the 5-year survival rate of $15.1 \%$ in $2004^{[6,7]}$.

New therapies approved by the FDA for use in the treatment of metastatic melanoma employ strategies to activate the immune system to target melanoma cells or use small molecules to target mutations activating signal transduction pathways. Briefly, novel immunotherapies include antibodies that prevent the activation of cell surface receptors that allow cancer cells to evade immune surveillance, including cytotoxic $\mathrm{T}$ lymphocyte-associated antigen 4 (CTLA-4) and programmed cell death protein-1/programmed cell death protein ligand-1 (PD-1/PD-L1). Targeted small molecules include B-RAF proto-oncogene (BRAF) inhibitors and mitogen-activated protein kinase (MEK) inhibitors used to diminish tyrosine kinase signaling pathways that affect cell division and differentiation ${ }^{[8]}$. The full description of these therapies is beyond the scope of this review.

In 2009, the pivotal phase III OPTiM [Oncovex (GM-CSF) Pivotal Trial in Melanoma] trial for an oncolytic virus, talimogene laherparepvec (T-VEC), directly injected into metastatic melanoma began ${ }^{[9]}$. Patients with biopsy-proven metastatic melanoma were eligible, including those with visceral metastases. It was an elegant trial design randomizing patients to intralesional injection of T-VEC (attenuated herpes simplex virus-1 encapsulating GM-CSF) vs. subcutaneous GM-CSF injection. The primary endpoint was a durable response rate, and the secondary endpoint was overall survival. In 2015, T-VEC was the first in class oncolytic virus (OV) approved by the FDA. Subsequently, T-VEC has shown promising results as both monotherapies and in combination with other immunotherapies ${ }^{[10,11]}$. In this review, we will discuss the development of T-VEC as a monotherapy, combination therapy, and neoadjuvant therapy, in addition to other OVs currently being studied for patients with melanoma and ongoing clinical trials.

\section{T-VEC}

\section{T-VEC: mechanism of action}

T-VEC is an oncolytic virus derived from the JS1 strain of herpes simplex virus-1 (HSV-1), which can infect skin, nerve, and immune cells and commonly causes herpes simplex labialis ${ }^{[12,13]}$. The oncologic specificity and oncolytic activity of the virus were developed through genetic modifications and serial passaging in cell lines to render it selective for infection and lysis of tumor cells and to help induce a T-cell mediated host anti-tumor immune response. At the injection site, selective viral replication within tumor cells leads to cell lysis, which also helps induce an active anti-tumor immune response with both local and systemic effects. Selective viral replication is achieved in part by deletion from the HSV-1 genome of the neurovirulence 
factor infected cell protein (ICP) $34.5^{[14]}$. With the deletion of ICP34.5, viral replication is limited to tumor cells, as non-tumor cells have native defenses that block viral replication ${ }^{[14-16]}$. Further, the deletion of ICP47 inhibits antigen presentation of infected cells and increases the expression of US11, further enhancing selective replication and, with accumulating viral replication, leads to cell lysis ${ }^{[17-20]}$. Third, the insertion of the gene GM-CSF results in local GM-CSF production, causing recruitment and activation of anti-tumor T cells and antigen-presenting cells, particularly dendritic cells, and results in both local and systemic changes favoring immunity against melanoma cells ${ }^{[14,21,22]}$. Overall, the three key genetic modifications, the deletion of ICP34.5, deletion of ICP47 with upregulation of US11, and insertion of GM-CSF, allow T-VEC to selectively replicate in tumor cells selectively, induce tumor cell lysis, and promote an enhanced $\mathrm{T}$ cell response.

\section{T-VEC: safety, biodistribution, and viral shedding}

Intralesional injection of T-VEC has been proven safe as the biodistribution, viral shedding, and risk of transmission associated with intralesional therapy have been evaluated in multiple studies ${ }^{[23-25]}$. The initial phase I trial included patients with cutaneous metastases from breast cancer, head and neck cancer, gastrointestinal cancer, or malignant melanoma to evaluate the safety profile of intralesional T-VEC ${ }^{[23]}$. Seronegative patients were shown to seroconvert within the first 4 weeks of receiving therapy. Viral DNA was only rarely identified in the blood and urine of patients shortly after injection, and no viral DNA was found to extend beyond the occlusive dressing over the injected tumor site. Overall, both viral replication and local inflammation diminished after 2-3 weeks, supporting a repeat dosing regimen on that schedule. Tumor site biopsies after receiving therapy showed that all areas of necrosis also stained positive for HSV, and there was no necrosis identified in normal tissue, supporting the selective replication of T-VEC in tumor cells ${ }^{[23]}$. This safety profile was confirmed in a phase I/II trial that evaluated the safety and utility of TVEC in patients with untreated stage III/IV head and neck squamous cell carcinoma. This study found no viral DNA external to the occlusive dressing, and all patients seroconverted following treatment ${ }^{[24]}$. A phase II trial for patients with unresectable stage IIIC/IV melanoma used intratumoral T-VEC with assessment for safety profile and clinical response ${ }^{[25]}$. Similar to the phase I trial, all HSV seronegative patients seroconverted following therapy initiation, and $<1 \%$ of swabs showed the presence of viral DNA within 24$72 \mathrm{~h}$ of the first dose, supporting only rare viral shedding at the injection site and beyond the occlusive dressing ${ }^{[25]}$.

Although prior studies have not shown any transmission of the T-VEC virus to patients, family members, or healthcare workers, a phase II, open-label study conducted after the OPTiM trial sought to better understand the biodistribution, viral shedding, and transmissibility of $\mathrm{T}-\mathrm{VEC}^{[23,26]}$. Swabs were collected at the injection site, occlusive dressing, and any lesions suspicious for being herpetic in addition to urine and blood samples. In this study, T-VEC DNA was identified in patients' blood and urine, on dressings and the surface of injected tumors, and rarely on the anogenital area and oral mucosa. Approximately $33 \%$ of blood samples contained viral DNA. Researchers also showed that all T-VEC DNA was cleared from blood and urine by the time patients completed T-VEC therapy. The surfaces of injected lesions demonstrated the highest incidence of detectable T-VEC DNA; however, no DNA was found on the surface of occlusive dressings, indicating that the dressing acts to protect against any viral transmission. Overall, this phase II study reinforces the safety of T-VEC therapy and the effectiveness of current practice methods to reduce the risk of transmission effectively ${ }^{[26]}$.

\section{ADMINISTRATION OF TVEC}

VEC administration necessarily involves the development of programs and procedures to not only select and monitor patients appropriate for therapy with T-VEC, but also for the safe preparation and 
administration of the OV. Our group has published our protocol and practical experience ${ }^{[27]}$. Implementing a T-VEC program requires multidisciplinary support from oncology physicians and advanced practice providers, radiologists, pharmacists, and nursing staff.

Pharmacists should be familiar with the storage, preparation, dosing, adverse effects, and drug interactions with T-VEC. The virus requires storage at -70 to $-90{ }^{\circ} \mathrm{C}$ until immediately prior to injection. The medication must be thawed in a USP797-compliant clean room in a biosafety hood and syringes drawn up in a laminar flow biosafety cabinet. Separate syringes are used for each injection site, and all transport is done with double-bagging and gloves. All surfaces involved in preparation must be cleaned with agents with viricidal activity.

Patients should be confirmed not to have any medications that would interact with T-VEC administration or cause immunosuppression. Patients are typically premedicated with acetaminophen, which is continued on a schedule for $24 \mathrm{~h}$ and thereafter as necessary, and prochlorperazine. Topical or injectable lidocaine and cryotherapy are employed prior to injection. Metastatic sites are measured with calipers and carefully documented at each visit, including photographs to document location of lesions and progression through treatment.

The initial cycle of T-VEC uses the virus at a concentration of $10^{6}$ plaque-forming units per $\mathrm{mL}$, and subsequent cycles use $10^{8}$ plaque-forming units per milliliter $(\mathrm{pfu} / \mathrm{mL})$. Four milliliters is the maximal dose for a single round of injection; this volume is typically divided proportionally among lesions to be injected. For lesions at the skin surface, injection is done with direct visualization and palpation. For deeper lesions, ultrasound guidance is employed ${ }^{[28]}$. All providers wear full personal protective equipment, including chemotherapy gowns, facemasks, eye protection, and sterile gloves. Injection sites are sterilely prepped and the OV injected. After injection, the skin is cleaned with alcohol to kill any live virus on the surface. An occlusive dressing is placed, and again the skin and dressing are cleaned with alcohol. Patients are observed for $15 \mathrm{~min}$ after injection to ensure no acute reactions. Patients are instructed to leave the dressing in place for seven days after the procedure.

The second cycle is typically given three weeks later, and subsequent cycles every two weeks. Treatment continues until there is evidence of complete response, intolerable side effects, or progression of the disease. Often, times biopsy is required to determine whether residual pigment at a site is viable melanoma. In cases of locally advanced disease, surgery may be performed after an adequate response to therapy has been achieved.

\section{T-VEC AS MONOTHERAPY}

\section{T-VEC as monotherapy: the OPTiM trial}

The OPTiM trial was a randomized phase III open-label trial evaluating the efficacy of T-VEC for patients with unresectable stage IIIB-IV melanoma ${ }^{[9,29]}$. The trial compared intralesional T-VEC with subcutaneous injection of GM-CSF. The study enrolled 436 participants across 64 sites in multiple countries. Participants were randomized 2:1 to receive either intralesional T-VEC or subcutaneous GM-CSF. For patients in the TVEC arm, the first dose received was $10^{6} \mathrm{pfu} / \mathrm{mL}$, followed by subsequent doses of $10^{8} \mathrm{pfu} / \mathrm{mL}$. The second dose was given 3 weeks after the initial dose, and subsequent doses were given at 2 -week intervals. For patients in the GM-CSF arm, $125 \mu \mathrm{g} / \mathrm{m}^{2}$ was given each day subcutaneously over a 14-day time course in an overall 28-day cycle. At 24-weeks, patients could continue treatment until the disease was progressing; treatment was intolerable, the patient withdrew consent, and complete remission was achieved. There was a lack of response by 12 months, or, for the T-VEC arm only, and all injectable lesions had disappeared. 
Median durations of treatment were 23.1 weeks and 10.0 weeks in the T-VEC and GM-CSF arms, respectively.

Analysis of the OPTiM trial occurred 3 years after randomization of the last patient enrolled. The primary outcome of the study was durable response rate (DRR), which investigators defined as either complete response (CR) or partial response (PR) that began within 12 months of receiving T-VEC and lasted for at least 6 months continuously. The DRR at the time of final analysis was significantly greater in those that received T-VEC (T-VEC arm 19.3\% vs. GM-CSF arm 1.4\%; $P<0.0001$ ). Secondary outcomes of the study included OS, best overall response rate (ORR), time to onset of response, duration of response, tumor burden, and time to treatment failure. In addition to the improvement in DRR, patients in the T-VEC arm had a significantly greater ORR of $31.5 \%$ compared to $6.4 \%$ in the GM-CSF arm $(P<0.0001)$. CR was achieved in $16.9 \%$ of patients that received T-VEC ( $v$ s. $0.7 \%$ in the GM-CSF arm). The median time to CR in patients that received T-VEC was 8.6 months. In an analysis that was not prespecified by investigators, the tolerability of T-VEC was evaluated by comparing the incidence of adverse events (AEs). This additional analysis demonstrated that the most common AEs reported were constitutional symptoms, mainly fever and fatigue. Eleven point three percent of patients who received T-VEC experienced grade $3 / 4 \mathrm{AEs}$ ( $v s .4 .7 \%$ of GM-CSF patients), most commonly cellulitis $(2.1 \%)^{[29]}$.

The systemic response generated by T-VEC may result in an abscopal effect. It is a similar mechanism that has been proposed in the systemic response mounted with the use of immunotherapies targeting PD-1/PDL1 or CTLA-4 pathways ${ }^{[30]}$. In the OPTiM trial, $64 \%$ of lesions injected with T-VEC demonstrated at least $50 \%$ regression. About half of the injected lesions demonstrated complete resolution, and non-injected lesions demonstrated at least 50\% regression in 34\% of non-visceral and 15\% of visceral lesions. From these findings and the clinical improvement observed in visceral and non-injected non-visceral lesions throughout the body and distant from the injection site, it can be assumed that the response seen in those areas is related to systemic effects of T-VEC. Similar to pseudoprogression that has been described in patients treated with other immunotherapies, greater than $50 \%$ of the patients' lesions that were treated by T-VEC grew at least $25 \%$ prior to showing response to treatment ${ }^{[30]}$. It serves as an important example of the delayed response that patients experience as a result of the systemic activation of defenses that require more time compared to the direct lysis mechanism of T-VEC that occurs at the tumor injection site. It also serves as a reminder that therapy should be continued even if the disease initially progresses.

\section{T-VEC: current approval and guidelines}

The DRR demonstrated in the OPTiM trial led to FDA approval in 2015 for use in the local treatment of unresectable recurrent subcutaneous, cutaneous, and nodal metastatic melanoma, becoming the first in class OV for cancer ${ }^{[31]}$. As demonstrated in subsequent sections in this review, although the approval for TVEC was in this limited clinical setting, in clinical practice and clinical trials, T-VEC is used more broadly and in combination and sequence with other therapies.

T-VEC has subsequently been incorporated into guidelines in the management of locally advanced and metastatic melanoma. National Comprehensive Cancer Network Guidelines include T-VEC among the initial treatments for stage III (clinical satellite/in-transit) disease ${ }^{[8]}$. T-VEC is included as first-line monotherapy for both unresectable disease and limited resectable disease. This is likely the most common clinical setting for the use of T-VEC, although increasingly T-VEC is also used for unresectable primary lesions and in combination with other therapeutic modalities. 


\section{T-VEC as monotherapy: further studies}

As new therapies emerge, it becomes vital to gain an understanding of which patients are best candidates for which therapy and how the different treatment options compare to each other with regard to efficacy and utility. Louie et al. ${ }^{[3]}$ performed a retrospective study to characterize results in clinical practice for patients with stage IIIB, IIIC, IIID, and distant metastatic disease at the time of treatment with T-VEC. Most patients included in this retrospective study had stage IIIB-IVM1a disease (67\%) and received a median of five cycles of T-VEC (range 1-14 cycles) with either no side effects or only mild constitutional symptoms. Twenty-four percent of lesions were in the head and neck area, an area that is notoriously difficult to manage and treat. Overall, 39\% of patients achieved a CR with T-VEC alone. An additional 11\% had surgical resection of their residual disease, and thus, 50\% of patients achieved a CR with T-VEC and surgery. Analysis showed that those with stage IIIB disease were significantly more likely to demonstrate complete local response (68\%) compared to those with more progressive disease, which agrees with the OPTiM trial finding that patients with less advanced disease were more likely to achieve $\mathrm{CR}^{[3,29]}$. Of the stage IIIB patients who received TVEC, 59\% still showed no evidence of disease at a median follow-up of 12 months. These findings further reinforce the safety and utility of T-VEC in general and, specifically, for lesions located at anatomic sites that are difficult to treat, like the head and neck, particularly if stage IIIB/C disease.

\section{T-VEC as monotherapy: ongoing clinical trials}

Given the clear success of the OPTiM trial and the increasing use of systemic immunotherapy, there are few trials still evaluating T-VEC as monotherapy. There are several ongoing studies to characterize the infectious risk and long-term safety profile of the treatment.

An ongoing prospective cohort study is seeking to identify the risk of infection with HSV in patients, close contacts, and healthcare providers related to patients treated with T-VEC, in addition to long-term safety for patients ${ }^{[32]}$. The study accrual goal is 920 patients, and the primary outcome measure is the incidence rate of the herpetic infection with detectable T-VEC DNA up to 5 years after the first dose of T-VEC was administered. Additional secondary outcome measures include the incidence of herpetic infection in healthcare workers, close contacts, and patients while receiving treatment and after treatment, the incidence of HSV-1 DNA in patients during and after treatment, demographics, use of other melanoma therapy, the incidence of AEs, and OS. The estimated completion date is August 28, 2026.

There is also an observational, prospective cohort study that plans to evaluate the OS, use of other therapies, and long-term safety profile of patients that have already received T-VEC in a prior clinical trial sponsored by either Amgen or BiOVEX for any type of malignancy ${ }^{[33]}$. This study aims to enroll 340 participants and will follow up with enrolled patients every 3 months. The primary outcome measures are the incidence of AEs related to T-VEC therapy, OS, and the use of other anti-cancer therapy. This study is actively enrolling patients by invitation and has an estimated completion date of January 12, 2023.

\section{T-VEC AS COMBINATION THERAPY}

\section{T-VEC as combination therapy: overview}

T-VEC monotherapy has proven to be an effective tool in the setting of advanced melanoma. Researchers have continued to explore the other applications of T-VEC as combination therapy in conjunction with other immunotherapies and treatments [Table 1] ${ }^{[4]}$. We will now review completed and ongoing clinical trials exploring the role of T-VEC in combination with systemic therapies.

\section{T-VEC as combination therapy: T-VEC plus ipilimumab}

Immunotherapy has become the primary treatment for advanced melanoma in recent years. Agents used include the anti-PD-1 antibodies nivolumab and pembrolizumab and the CTLA-4 inhibitor ipilimumab. 
Table 1. Current combination trials with T-VEC and systemic therapy

\begin{tabular}{|c|c|c|c|c|c|c|c|c|}
\hline Title & Status & Intervention & Phase & $\begin{array}{l}\text { Study } \\
\text { design }\end{array}$ & $\begin{array}{l}\text { Primary } \\
\text { outcome }\end{array}$ & Enrollment & $\begin{array}{l}\text { Start } \\
\text { date }\end{array}$ & $\begin{array}{l}\text { End } \\
\text { date }\end{array}$ \\
\hline $\begin{array}{l}\text { Ipilimumab with or without } \\
\text { talimogene laherparepvec in } \\
\text { unresected melanoma }\end{array}$ & Completed & T-VEC, Ipilimumab & $1 b, 2$ & Single group & DLT, ORR & 217 & $\begin{array}{l}\text { February } \\
7,2013\end{array}$ & $\begin{array}{l}\text { March 9, } \\
2021\end{array}$ \\
\hline $\begin{array}{l}\text { Pembrolizumab with or without } \\
\text { talimogene laherparepvec or } \\
\text { talimogene laherparepvec } \\
\text { placebo in unresected melanoma } \\
(\text { KEYNOTE-034) })^{[39]}\end{array}$ & Terminated & $\begin{array}{l}\text { Pembrolizumab with T- } \\
\text { VEC vs. Pembrolizumab } \\
\text { with placebo }\end{array}$ & 3 & Randomized & $\begin{array}{l}\text { DLT, PFS, } \\
\text { OS }\end{array}$ & 713 & $\begin{array}{l}\text { December } \\
8,2014\end{array}$ & $\begin{array}{l}\text { March } \\
11,2021\end{array}$ \\
\hline $\begin{array}{l}\text { Combining talimogene } \\
\text { laherparepvec with BRAF and } \\
\text { MEK inhibitors in BRAF mutated } \\
\text { advanced melanoma }{ }^{499]}\end{array}$ & $\begin{array}{l}\text { Active, not } \\
\text { recruiting }\end{array}$ & $\begin{array}{l}\text { T-VEC, } \\
\text { Dabrafenib/Trametinib }\end{array}$ & 1 & Single group & DLT & 4 & $\begin{array}{l}\text { June 25, } \\
2017\end{array}$ & $\begin{array}{l}\text { June 30, } \\
2021\end{array}$ \\
\hline $\begin{array}{l}\text { Neoadjuvant combination } \\
\text { immunotherapy for stage III } \\
\text { melanoma }{ }^{[64]}\end{array}$ & Recruiting & T-VEC, Pembrolizumab & 2 & Single group & $\mathrm{pCR}$ & 28 & $\begin{array}{l}\text { July 3, } \\
2019\end{array}$ & $\begin{array}{l}\text { March 1, } \\
2022\end{array}$ \\
\hline $\begin{array}{l}\text { Talimogene laherparepvec and } \\
\text { pembrolizumab in treating } \\
\text { patients with stage III-IV } \\
\text { melanoma }{ }^{[41]}\end{array}$ & $\begin{array}{l}\text { Active, not } \\
\text { recruiting }\end{array}$ & T-VEC, Pembrolizumab & 2 & Single group & ORR & 47 & $\begin{array}{l}\text { October 2, } \\
2017\end{array}$ & $\begin{array}{l}\text { June } 30 \\
2023\end{array}$ \\
\hline $\begin{array}{l}\text { Talimogene laherparepvec with } \\
\text { pembrolizumab in melanoma } \\
\text { following progression on prior } \\
\text { Anti-PD-1 based therapy } \\
\text { (MASTERKEY-115) (Mk-3475- } \\
\text { A07/KEYNOTE-A07) } \text { [42] }^{-1}\end{array}$ & $\begin{array}{l}\text { Active, not } \\
\text { recruiting }\end{array}$ & T-VEC, Pembrolizumab & 2 & Single group & OR & 72 & $\begin{array}{l}\text { January } \\
22,2020\end{array}$ & $\begin{array}{l}\text { February } \\
26,2024\end{array}$ \\
\hline
\end{tabular}

DLT: Dose-limiting toxicity; ORR: overall response rate; PFS: progression-free survival; OS: overall survival; pCR: pathologic complete response; OR: overall response.

These medications can be used as both monotherapy and combination therapy in patients with advanced melanoma.

In a phase Ib open-label, single-arm trial, researchers sought to explore the safety and efficacy of T-VEC in combination with ipilimumab for patients with unresectable, stage IIIB-IV melanoma ${ }^{[34]}$. Nineteen patients were recruited across five clinical sites within the United States. Each patient had injectable lesions and had not received any systemic adjuvant therapy within at least 6 months. Eighteen patients were included in the analysis, as the other patient withdrew from the study after one dose of T-VEC to enroll in hospice care. TVEC and ipilimumab were administered as the same dose given when each therapy is used as a monotherapy. Patients received T-VEC as monotherapy initially, and ipilimumab was started at week 6 for a total of four infusions. T-VEC was continued until patients achieved CR, all injectable lesions resolved, the disease progressed based on immune-related response criteria, or the patient could no longer tolerate the drug. Forty-two percent of the patients had stage IIIB-IVM1a melanoma, and the remaining $58 \%$ had stage IVM1b/c melanoma.

No dose-limiting toxicities (DLTs) were reported by patients, and no AEs resulted in therapy discontinuation. Grade 3/4 AEs occurred at an incidence of $26.3 \%$, similar to that which occurs with ipilimumab as monotherapy. Twenty-two percent of patients demonstrated durable CRs. Of those patients, at the 1-year analysis, all of them had maintained CR. Researchers also showed that total and activated CD8+ T cells significantly increased following the initiation of T-VEC therapy. Activated CD8+ T cells increased by 1.51 -fold, and the increase in these activated $\mathrm{T}$ cells corresponded with patient response to therapy ${ }^{[34]}$. 
The phase II portion of this trial was a randomized, open-label study designed to compare ipilimumab alone $v s$. ipilimumab plus T-VEC in patients with unresectable stage IIIB-IV melanoma ${ }^{[35]}$. One hundred and ninety-eight patients were randomly assigned 1:1 into the two treatment arms. Ninety-eight patients were allocated to receive T-VEC plus ipilimumab. One hundred patients were allocated to receive ipilimumab only. Like the phase Ib trial, patients in the combination arm received T-VEC in week 1, followed by the second dose 3 weeks later, and each subsequent dose was given at 2-week intervals. Ipilimumab was started in week 6 in the combination arm $v s$. week 1 in the ipilimumab alone arm. The primary outcome measure was ORR. Secondary outcome measures included safety of ipilimumab plus T-VEC, OS, best overall response, rate of disease control, time to response, duration of response, and progression-free survival $(\mathrm{PFS})^{[35]}$.

The incidence of AEs and tolerability of ipilimumab plus T-VEC paralleled the observations and findings from the phase Ib study, showing no increase in the incidence of severe AEs in the combination arm. Combination therapy with T-VEC and ipilimumab resulted in a greater ORR compared to ipilimumab alone [odds ratio $(\mathrm{OR})=2.9 ; 95 \% \mathrm{CI}: 1.5-5.5 ; P=0.002$ ]. Patients that received T-VEC plus ipilimumab demonstrated an ORR of $39 \%$ (vs. ipilimumab alone arm, ORR of $18 \%$ ). Regarding the increase in activated and total CD8+ T cells that were identified in the phase $\mathrm{Ib}$ portion of the trial, a subset analysis in the phase II study supports an enhanced systemic immune response with T-VEC therapy based on greater rates of complete visceral tumor regression in the combination arm compared to patients treated with ipilimumab alone (combination arm 23\%; ipilimumab alone $0 \%$ ). The OS of patients that received combination therapy had not yet been reached at the time of this data analysis ${ }^{[35]}$.

The 4-year interim analysis of the phase II data reported as an abstract at this time, shows even more encouraging findings in support of the continued benefit of combination therapy with T-VEC plus ipilimumab, including an improved DRR and PFS compared to patients that received ipilimumab alone ${ }^{[36]}$. In the combination arm, DRR was $33.7 \%$ compared to $13.0 \%$ in the ipilimumab only arm $(\mathrm{OR}=3.4 ; 95 \% \mathrm{CI}$ : 1.7-7.0; $P=0.001)$, and median PFS was 13.5 months compared to 6.4 months in the ipilimumab only arm $(\mathrm{HR}=0.81 ; 95 \% \mathrm{CI}: 0.57-1.15 ; P=0.23)$. Fewer patients who received combination therapy required treatment with subsequent therapy ( $48.0 \%$ vs. $64 \%$ in the ipilimumab only arm). At the time of the 4 -year interim analysis, median OS for the combination arm was still yet to be reached. The median OS in the ipilimumab arm was 50.1 months. A subgroup analysis was done of patients based on BRAF V600 mutation, with similar patient ratios in both the combination arm and ipilimumab arm. Of patients that lacked the BRAF V600 mutation (approximately $60 \%$ of patients in each treatment arm), DRR and median PFS were both enhanced in the combination arm compared to patients that received only ipilimumab (DRR: 33.9 vs. 5.0\%, respectively; median PFS: 18.0 months vs. 4.5 months, respectively). Interestingly, patients with a BRAF V600 mutation demonstrated similar DRR and median PFS across treatment arms. This study was completed in March 2021, and the final report is pending ${ }^{[36]}$.

The data reported from the phase II trial was further analyzed to evaluate the presence of pseudoprogression, a phenomenon that has been described in the context of immunotherapy ${ }^{[37]}$. Pseudoprogression can be understood as a delayed measurable response to therapy, in which measurable tumors enlarge secondary to immune-cell infiltration and inflammation for a period of time prior to receding. Delayed response to therapy and even development of new lesions may be seen prior to evidence of response. In this analysis, patients with a confirmed objective response in either treatment arm were included for this additional analysis. Of those in the combination therapy arm, 7 of 38 patients who had an OR demonstrated pseudoprogression. Pseudoprogression occurred more frequently in the combination arm than in the ipilimumab arm ( 1 of 18 patients with OR). Experiencing pseudoprogression after therapy 
with T-VEC plus ipilimumab was found to be associated with higher ORR (ipilimumab plus T-VEC 39\%; control arm, 18\%). Most delayed responses developed before week 12 following the initiation of therapy. The $18 \%$ incidence of delayed response to ipilimumab plus T-VEC suggests that providers should monitor for a response for at least 3 months before deeming a patient's disease resistant to therapy ${ }^{[37]}$.

\section{T-VEC as combination therapy: T-VEC plus pembrolizumab}

Research suggests that patients with melanoma are more likely to respond to therapy that targets the PD1/PD-L1 pathway if the tumor microenvironment (TME) has a greater CD8+ T cell density ${ }^{[10]}$. An openlabel, single-arm phase Ib trial, the MASTERKEY-265 trial, was conducted to evaluate the safety of combination therapy with T-VEC plus pembrolizumab and assess the capacity of T-VEC to prime the TME to best respond to anti-PD-1 therapy in patients with stage IIIB-IVM1c melanoma ${ }^{[10]}$. As reported based on findings of various studies, including the OPTiM trial, initiation of T-VEC therapy has shown to be associated with an increase in CD8+ T cells, promoting a more inflammatory TME associated with an enhanced response to immunotherapies ${ }^{[34,38]}$. In this phase Ib trial, 21 patients were enrolled to receive TVEC in combination with pembrolizumab ${ }^{[10]}$. The TME was evaluated via biopsies throughout the trial, including at baseline, after initiation of T-VEC therapy but prior to the first dose of pembrolizumab, and, when practical, following the initiation of pembrolizumab. Patients received the first dose of T-VEC of up to $4 \mathrm{~mL}$ of $10^{6} \mathrm{pfu} / \mathrm{mL}$. Each subsequent dose was $10^{8} \mathrm{pfu} / \mathrm{mL}$. The second T-VEC dose was given three weeks later, after which each T-VEC dose was given every two weeks. Pembrolizumab was administered intravenously at a dose of $200 \mathrm{mg}$ every 2 weeks, and the first dose was given 5 weeks following the initiation of T-VEC therapy.

The primary outcome measure of the phase Ib study was the incidence of DLTs associated with T-VEC and pembrolizumab combination therapy. At the 3-year analysis, no patients in the study experienced unexpected AEs or therapy-related toxicities outside of those reported in studies assessing the safety and side effect profile of T-VEC and pembrolizumab as monotherapies. Fatigue (62\%), chills (48\%), and pyrexia (43\%) were the most common treatment-related side effects with T-VEC therapy. The ORR was $61.9 \%$ (95\%CI: 38.4\%-81.9\%). Thirty-three point three percent of patients achieved CR (95\%CI: $14.6 \%-57.0 \%$ ). Of the 21 patients, 9 demonstrated a delayed response consistent with the pseudoprogression associated with T-VEC therapy prior to receiving the first dose of pembrolizumab. Of the injected lesions, $82 \%$ regressed greater than $50 \%$. Of non-injected lesions, $43 \%$ of visceral lesions and $33 \%$ of non-visceral lesions regressed greater than $50 \%$. At the time of the initial analysis, PFS and OS were yet to be reached ${ }^{[10]}$.

Immunohistochemical analysis compared biopsies from before and after the initiation of T-VEC therapy, showing that 8 of 12 lesions analyzed demonstrated an increase in the presence of infiltrating CD8+ T cells. Important findings regarding the TME include the increased density of CD8+ T cells and an increase in cellular expression of PD-L1, which was identified in $80 \%$ of injected tumors and $50 \%$ of non-injected tumors. These two changes mechanistically allow for an enhanced response to anti-PD- 1 therapy ${ }^{[10]}$.

Long-term follow-up analysis of the phase Ib trial was reported in an abstract at the almost 5-year mark ${ }^{[39]}$. This analysis included the 15 patients that were still alive (study enrollment occurred from December 2014 to March 2015; data cut-off for long-term analysis was in March 2020). Analysis at this approximately 5year follow-up showed no additional safety concerns. The maximum treatment period of patients in the study was 2 years, and the median follow-up time was 58.6 months. CR was achieved in 43\% (9/21 patients). The overall ORR was $62 \%$. The 4-year Kaplan-Meier (KM) estimated PFS and OS were $55.9 \%$ and $71.4 \%$, respectively, and median PFS and OS had not yet been achieved. Of the patients that responded to combination therapy with T-VEC plus pembrolizumab, $92 \%$ remained in response at the time of the long- 
term follow-up. To highlight the difference in OS between patients that did and did not respond to T-VEC plus pembrolizumab, the median OS in those that did not respond was 24.4 months compared to those that responded, for which the median OS had not yet been achieved ${ }^{[39]}$.

The randomized phase III portion of the MASTERKEY-265 clinical trial, assessing the overall efficacy of TVEC in combination with pembrolizumab vs. pembrolizumab alone, was closed in March 2021, with results yet to be reported ${ }^{[40]}$. It has enrolled a total of 713 participants who have been randomized to receive either T-VEC plus pembrolizumab or placebo injection plus pembrolizumab. The primary outcome measures of this phase III trial are the PFS and OS of patients that receive T-VEC plus pembrolizumab vs. placebo plus pembrolizumab.

Several additional studies are currently ongoing to further evaluate the role of T-VEC and pembrolizumab as combination therapy in patients with advanced melanoma [Table 2]. A single-arm, open-label phase II trial is currently ongoing and studying the efficacy and ORR of T-VEC plus pembrolizumab in patients with stage III-IV melanoma who have progressed on prior therapy that included an anti-PD-1 or anti-PD-L1

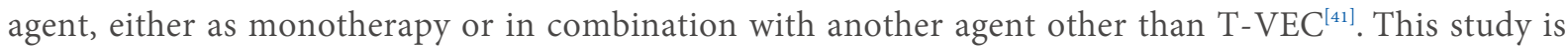
active and not recruiting additional patients. The estimated completion date is in June 2023. An additional open-label, single-arm, multicenter phase 2 trial (MASTERKEY-115) is assessing the safety and efficacy of T-VEC plus pembrolizumab as combination therapy in patients with stage IIIB-IVM1d melanoma who have experienced disease progression while receiving anti-PD-1 therapy or with prior adjuvant anti-PD-1 therapy ${ }^{[42]}$. This study is currently active and is no longer recruiting patients. The estimated completion date is in January 2022. Finally, a non-randomized, open-label, multicenter phase 1b/2 trial (MASTERKEY-318) is assessing the efficacy and safety of intratumoral T-VEC in liver tumors as either monotherapy or in combination with pembrolizumab ${ }^{[43]}$. The study involves two groups of patients, distinguished based on the underlying disease. Group A will involve patients with non-hepatocellular carcinoma (HCC) liver metastases, including melanoma. Group B will include patients with HCC. This study is currently recruiting patients and has an estimated completion date of October 25, 2022.

\section{T-VEC as combination therapy: institutional series}

In addition to the trials reported above, several institutions have published their experience in treating patients with a combination of T-VEC and immunotherapy, including pembrolizumab, nivolumab, or combination nivolumab/ipilimumab. A retrospective analysis reviewed the cases of 10 patients with stage III-IVM1b melanoma treated at the Cleveland Clinic with T-VEC plus either pembrolizumab, nivolumab, or nivolumab plus ipilimumab ${ }^{[44]}$. Eighty percent of these patients had unresectable stage III melanoma. The remaining $20 \%$ had stage IV disease with lung metastases. All doses of T-VEC, pembrolizumab, and nivolumab plus ipilimumab were administered three weeks apart. Nivolumab was given every two weeks. The timing at which patients started checkpoint inhibitors varied across the group, 4 of which initiated checkpoint inhibitor therapy prior to the first dose of T-VEC. Eighty percent of patients included in this analysis received T-VEC plus pembrolizumab. The overall ORR was $90 \%$. CR was achieved in $60 \%$ of patients, while PR was achieved in $30 \%$. A similar analysis at a single institution analyzed 30 patients with advanced melanoma treated with T-VEC plus an immune checkpoint inhibitor between 2016 and $2019^{[45]}$. Fifty-three percent of the patients had stage IV disease. Median follow-up was 17.5 months. The patients were treated with T-VEC plus either pembrolizumab $(n=18)$, nivolumab $(n=7)$, or ipilimumab plus nivolumab $(n=5)$. ORR was $80 \%$. CR and PR were achieved in $50 \%$ and $30 \%$, respectively. Both of these analyses demonstrate significant patient response rates in the practice setting when treated with T-VEC in combination with a selection of checkpoint inhibitors. 
Table 2. Current combination trials with T-VEC and local/regional therapy

\begin{tabular}{|c|c|c|c|c|c|c|c|c|}
\hline Title & Status & Intervention & Phase & $\begin{array}{l}\text { Study } \\
\text { design }\end{array}$ & $\begin{array}{l}\text { Primary } \\
\text { outcome }\end{array}$ & Enrollment & Start date & $\begin{array}{l}\text { End } \\
\text { date }\end{array}$ \\
\hline $\begin{array}{l}\text { Efficacy and safety of talimogene } \\
\text { laherparepvec neoadjuvant } \\
\text { treatment plus surgery versus } \\
\text { surgery alone for melanoma }\end{array}$ & $\begin{array}{l}\text { Active, not } \\
\text { recruiting }\end{array}$ & $\begin{array}{l}\text { Surgery vs. } \\
\text { neoadjuvant T- } \\
\text { VEC with surgery }\end{array}$ & 2 & Randomized & RFS & 150 & $\begin{array}{l}\text { February 3, } \\
2015\end{array}$ & $\begin{array}{l}\text { April 30, } \\
2022\end{array}$ \\
\hline $\begin{array}{l}\text { A study of T-VEC (talimogene } \\
\text { laherparepvec) with or without } \\
\text { radiotherapy for melanoma, merkel } \\
\text { cell carcinoma, or other solid } \\
\text { tumors }{ }^{[54]}\end{array}$ & $\begin{array}{l}\text { Active, not } \\
\text { recruiting }\end{array}$ & $\begin{array}{l}\mathrm{T}-\mathrm{VEC} \text {, } \\
\text { radiotherapy }\end{array}$ & 2 & Single group & $\mathrm{RR}$ & 19 & $\begin{array}{l}\text { June 21, } \\
2016\end{array}$ & $\begin{array}{l}\text { June } \\
2022\end{array}$ \\
\hline $\begin{array}{l}\text { Intratumoral injection of autologous } \\
\text { CD1c (BDCA-1)+ myeloid dendritic } \\
\text { cells plus talimogene laherparepvec } \\
(T-V E C)^{[50]}\end{array}$ & $\begin{array}{l}\text { Active, not } \\
\text { recruiting }\end{array}$ & $\begin{array}{l}\text { T-VEC, CD1c } \\
(B D C A-1)+\text { myDC }\end{array}$ & 1 & Single group & $\begin{array}{l}\text { Safety and } \\
\text { tolerability }\end{array}$ & 18 & $\begin{array}{l}\text { September } \\
28,2018\end{array}$ & $\begin{array}{l}\text { October } \\
1,2023\end{array}$ \\
\hline $\begin{array}{l}\text { Neoadjuvant T-VEC in high risk } \\
\text { early melanoma }{ }^{[57]}\end{array}$ & Recruiting & $\begin{array}{l}\text { Neoadjuvant T- } \\
\text { VEC }\end{array}$ & 2 & Single group & $\mathrm{pCR}$ & 62 & $\begin{array}{l}\text { May 21, } \\
2020\end{array}$ & $\begin{array}{l}\text { May 21, } \\
2024\end{array}$ \\
\hline $\begin{array}{l}\text { TITAN (tumoural injection of T-VEC } \\
\text { and isolated limb perfusion) }\end{array}$ & $\begin{array}{l}\text { Active, not } \\
\text { recruiting }\end{array}$ & $\begin{array}{l}\text { T-VEC, isolated } \\
\text { limb perfusion }\end{array}$ & 1,2 & Single group & $\begin{array}{l}\text { Safety and } \\
\text { tolerability, } \\
\text { RR }\end{array}$ & 15 & $\begin{array}{l}\text { June 26, } \\
2018\end{array}$ & $\begin{array}{l}\text { August 1, } \\
2024\end{array}$ \\
\hline
\end{tabular}

RFS: Recurrence-free survival; RR: response rate; pCR: pathologic complete response.

\section{T-VEC as combination therapy: braf/mek inhibitors}

Activating mutations of BRAF may be present in up to half of melanoma cases. A prior phase III study showed improvement in both OS and relapse-free survival when utilizing BRAF/MEK inhibitors, dabrafenib plus trametinib, in patients with V600E or V600K BRAF mutations ${ }^{[46]}$. Unfortunately, treatment with such therapy is greatly limited by resistance, with a reported median duration of the response being anywhere from merely 5.6-9.5 months ${ }^{[47]}$. A preclinical study has shown promising anti-tumor activity in a murine breast cancer model when using OVs in combination with MEK inhibitors, emphasizing a potential therapy opportunity for patients with advanced melanoma ${ }^{[48]}$.

Bommareddy et al. ${ }^{[11]}$ studied anti-tumor activity of T-VEC in combination with trametinib in melanoma. Using a murine xenograft model, they demonstrated enhanced tumor regression and improved delay in tumor growth when using T-VEC plus trametinib, a highly selective MEK inhibitor, compared to either therapy alone. Thirty to forty percent of mice that were treated with T-VEC and trametinib demonstrated complete tumor eradication. Based on the increased expression of PD-1 and PD-L1 observed in the mice that received T-VEC, researchers evaluated if there was any increased clinical benefit in treating with triple combination therapy with T-VEC, trametinib, and pembrolizumab. The findings show an improved durable response when using triple therapy ( $6 / 7$ mice) compared to T-VEC plus trametinib (2/7 mice). They also studied melanoma cell lines with BRAF V600E mutations to explore the impact of T-VEC in combination with either trametinib or vemurafenib, a BRAF inhibitor. Vemurafenib enhanced T-VECinduced cell lysis in only cells that contained the mutation. The application of trametinib enhanced T-VEC replication and oncolysis regardless of BRAF-mutation status. This important finding highlights the potential utility of MEK inhibition regardless of BRAF-mutation status. However, clinical studies will be needed to further understand how this translates to patient care. Overall, this preclinical study demonstrated synergistic tumor cell killing in vivo and in vitro when using T-VEC in combination with trametinib and proposes a role for triple combination therapy with T-VEC, MEK inhibitors, and anti-PD1/PD-L1 therapies.

The only current clinical trial evaluating T-VEC in combination with BRAF/MEK inhibitors in advanced melanoma is a single-arm open-label phase $\mathrm{Ib}$ trial ${ }^{[49]}$. This trial is designed to assess the safety and efficacy 
of T-VEC plus dabrafenib and trametinib in patients with stage IIIB-IVM1c melanoma with a BRAF mutation for whom surgical management is not recommended. If the therapy is being given the first line, the patient must have either a BRAF V600E or BRAF V600K mutation. If the patient's cancer had progressed on prior immunotherapy, the patient could have any type of BRAF mutation. The study is currently ongoing and has completed enrollment with a total of 4 patients. Each patient will receive T-VEC plus dabrafenib and trametinib. T-VEC will be administered according to the dose approved by manufacturers. Patients will also receive dabrafenib $150 \mathrm{mg}$ orally twice daily and trametinib $2 \mathrm{mg}$ orally once daily. Each therapy can be continued for up to two years. The primary outcome measure of this study is the rates of DLTs. Secondary outcome measures include PFS, ORR, changes in tumor burden, duration of response, and time to response. The estimated primary completion date was in November 2020, and the estimated study completion date is in June $2021^{[49]}$.

\section{T-VEC as combination therapy: other therapies}

In addition to the medical therapies discussed, several other clinical trials are currently evaluating the use of T-VEC in combination with other local/regional therapies [Table 2]. A single-arm, open-label phase I trial is evaluating the safety and tolerability of T-VEC plus autologous CD1c (BDCA-1)+ myeloid dendritic cells (myDCs) in patients with unresectable advanced melanoma with non-visceral metastases that are accessible for injection ${ }^{[50]}$. myDCs have been shown to play a critical role in the regulation of cytotoxic $\mathrm{T}$ cells with regard to tumor-killing activity ${ }^{[51]}$. Animal studies have shown that myDCs travel to lymph nodes and act as antigen-presenting cells to $\mathrm{T}$ cells, catalyzing the tumor-specific $\mathrm{T}$ cell response $\mathrm{e}^{[2]}$. This phase I trial seeks to evaluate the efficacy of T-VEC plus CD1c (BDCA-1)+ myDC, expecting that there may be a synergistic response due to the increase in the TME inflammation associated with T-VEC therapy. The primary outcome measure is treatment-related AEs, and the study has enrolled 18 patients. Each patient will receive intratumoral T-VEC plus CD1c (BDCA-1)+ myDC. The estimated primary completion date is in October 2023. This trial is currently ongoing and is no longer recruiting patients ${ }^{[50]}$.

Two treatments that have been applied as melanoma therapy more frequently in the past are being studied to assess if their utility is improved in combination with T-VEC. A non-randomized phase I/II trial is evaluating the safety of using T-VEC in combination with chemotherapy administered via isolated limb perfusion (ILP) ${ }^{[53]}$. Fifteen patients have been enrolled, each of which will receive 2 doses of T-VEC preoperatively, followed by a third dose given with the ILP, including melphalan and TNF- $\alpha$. Primary outcome measures are the incidence of DLTs and AEs and the incidence of CR and PR. No results have been reported, and the estimated primary completion date is in August 2022. The trial is currently ongoing and no longer recruiting patients. Additionally, a randomized, single-arm phase II trial is currently ongoing to evaluate the effects of T-VEC when administered with or without hypofractionated radiotherapy in patients with either melanoma, Merkel cell carcinoma, or other solid tumors with skin metastases ${ }^{[54]}$. The study aims to enroll 34 patients who will then be randomized to receive T-VEC either with or without radiotherapy. Each patient will receive T-VEC at weeks 0 , 3, 5, 7, 9, 11, 13, and 15. Patients in the T-VEC plus radiotherapy arm will also undergo radiotherapy treatments three times. These will occur during weeks 3 and 4 , occurring once every 3-5 days. The first will occur $4-8 \mathrm{~h}$ after the week 3 dose of T-VEC is administered. The primary outcome measure is the extent of the response to therapy, as measured by imaging. No results have been reported. The study is currently ongoing and recruiting patients.

\section{T-VEC AS NEOADJUVANT THERAPY}

\section{T-VEC as neoadjuvant therapy: overview}

Neoadjuvant therapy is used in advanced cancers to improve resectability of primary lesions, assess treatment response to specific therapies, provide time for completion of genetic studies and additional consults, and potentially treat systemic disease with greater tolerability and at an earlier time than if given 
after surgery ${ }^{[55,56]}$. In addition, when immunotherapy is used, there may be a benefit to initiating therapy when there is still a maximal neoantigen presence from the tumor. There are currently multiple ongoing clinical trials exploring the efficacy of T-VEC alone and in combination with other therapies in the neoadjuvant setting.

\section{T-VEC as neoadjuvant monotherapy}

A single-arm, open-label phase II study is studying the efficacy of neoadjuvant T-VEC in patients with highrisk, resectable melanoma prior to surgical excision ${ }^{[57]}$. The primary outcome measure is the degree of pathologic response, defined as either complete, major, partial, or no pathologic response. The estimated primary completion date is in May 2022, and the study is currently recruiting patients.

A randomized, open-label phase II study across multiple sites is evaluating the role of T-VEC as neoadjuvant therapy prior to surgery $v s$. surgery alone in patients with completely resectable stage IIIBIVM1a melanoma ${ }^{[58]}$. Interim results have thus far been reported as abstracts ${ }^{[5-61]}$. One hundred fifty patients were enrolled in the trial and randomized to receive either 6 doses of T-VEC over a period of 13-18-weeks followed by surgical resection or immediate surgical resection. Patients in the surgery alone arm may receive additional adjuvant therapy as needed based on the standard of care. At least $94 \%$ of patients enrolled in the study were naïve to any systemic or radiation therapy, and $91 \%$ had received a prior surgery ${ }^{[59]}$. The primary outcome measure of this study is RFS. Additional secondary outcome measures include RFS at 1- and 2-year follow-up, rate of tumor-free margins postoperatively (Ro), pCR, local and regional RFS, distant metastases-free survival rate, OS, best overall tumor response, ORR for injected and non-injected lesions, and incidence of $\mathrm{AEs}^{[58]}$.

Interim analysis of the trial data was conducted after the 75th patient in the neoadjuvant T-VEC arm completed a follow-up visit at least 30 days postoperatively ${ }^{[59]}$. Mainly due to disease progression, only $75 \%$ of patients in the neoadjuvant T-VEC plus surgery arm underwent surgery compared to $93 \%$ of patients in the surgery arm. For patients who underwent neoadjuvant T-VEC and surgery, $21 \%$ achieved pCR. The Ro resection rate was $56.1 \%$, compared to $40.6 \%$ in the surgery alone arm. Intent-to-treat 1-year RFS rates were $33.5 \%$ vs. $21.9 \%$ in the neoadjuvant T-VEC plus surgery arm compared to the surgery alone arm, respectively $(\mathrm{HR}=0.73, P=0.048)^{[60]}$. In addition to Ro and 1-year RFS, OS rates were trending towards superiority in the neoadjuvant T-VEC plus surgery arm (95.9\% T-VEC plus surgery, $85.8 \%$ surgery alone; $\mathrm{HR}=0.47, P=0.076)$.

In addition to demonstrating that neoadjuvant T-VEC resulted in improved RFS and OS at two years, the 2year analysis reported an increase in intratumoral CD8+ T cells and expression of PD-L1 in patients treated with neoadjuvant $\mathrm{T}$-VEC ${ }^{[61]}$. In the neoadjuvant $\mathrm{T}$-VEC arm plus surgery compared to the surgery alone arm, respectively, 2-year RFS rates were $50.5 \%$ vs. 30.2\% ( $\mathrm{HR}=0.66, P=0.038$ ), and 2-year OS rates were $88.9 \%$ vs. $77.4 \%(\mathrm{HR}=0.49, P=0.050)$. The analysis identified a correlation between greater intratumoral $\mathrm{CD} 8+\mathrm{T}$ cell density and longer RFS and OS. The 3-year interim analysis was most recently reported, including data as of April 2020 ${ }^{[62]}$. The median follow-up was 41.3 months, and this analysis continued to support the improvement in RFS and OS with the application of neoadjuvant T-VEC compared to immediate surgical resection. Comparing the neoadjuvant T-VEC plus surgery arm to the surgery alone arm, 3-year RFS KM estimates were $46.5 \%$ vs. 31.0\% ( $\mathrm{HR}=0.67, P=0.043)$, respectively, and 3-year OS KM estimates were $83.2 \%$ vs. $71.6 \%$ ( $\mathrm{HR}=0.60, P=0.022)$, respectively. Each phase II trial analysis has reported no new safety or toxicity concerns in either treatment arm. The results from this 3-year interim analysis are very encouraging for the role of neoadjuvant T-VEC in this patient population, and the final 5-year analysis results are greatly anticipated ${ }^{[58]}$. 
Table 3. Novel oncolytic viruses in clinical trials for melanoma

\begin{tabular}{|c|c|c|c|c|c|}
\hline Oncolytic virus & $\begin{array}{l}\text { Progenitor } \\
\text { virus }\end{array}$ & Mechanism of action & Company & $\begin{array}{l}\text { Route of } \\
\text { delivery }\end{array}$ & $\begin{array}{l}\text { Combinations } \\
\text { being tested }\end{array}$ \\
\hline $\begin{array}{l}\text { V937 (CAVATAK, } \\
\text { CVA21) }\end{array}$ & $\begin{array}{l}\text { Coxsackivirus } \\
\text { A21 }\end{array}$ & Targets ICAM-1, DAF ${ }^{[66-68]}$ & Merck & $\begin{array}{l}\text { Intratumoral } \\
\text { Intravenous }\end{array}$ & $\begin{array}{l}\text { Monotherapy } \\
\text { Ipilimumab } \\
\text { Pembrolizumab }\end{array}$ \\
\hline BT-001 (TG6030) & Vaccinia & $\begin{array}{l}\text { Expresses 4-E03 human recombinant anti- } \\
\text { hCTLA4 antibody and GM-CSF }{ }^{669]}\end{array}$ & $\begin{array}{l}\text { Biolnvent, } \\
\text { Transgene }\end{array}$ & Intratumoral & Pembrolizumab \\
\hline $\begin{array}{l}\text { Pexa-Vec (JX-594, } \\
\text { Pexastimogene } \\
\text { Devacirepvec) }\end{array}$ & Vaccinia & $\begin{array}{l}\text { Expresses GM-CSF; Deletion of thymidine } \\
\text { kinase }^{[67,68]}\end{array}$ & SillaJen & Intratumoral & $\begin{array}{l}\text { Monotherapy } \\
\text { Ipilimumamb }\end{array}$ \\
\hline TILT-123 & Adenovirus & $\begin{array}{l}\text { Expresses TNF-alpha and IL-2, enhancing T- } \\
\text { cell presence in the tumor } \\
\text { microenvironment }{ }^{[70]}\end{array}$ & $\begin{array}{l}\text { TILT } \\
\text { Biotherapeutics }\end{array}$ & Intratumoral & TILs \\
\hline ONCOS-102 & Adenovirus & $\begin{array}{l}\text { Expresses GM-CSF and Ad5/3 chimeric } \\
\text { capsid; induces anti-tumor immunity, CD8+ } \\
\text { T cell migration to tumor cells, upregulates } \\
\text { PD-L1 } 1^{[71,72]}\end{array}$ & Targovax Oy & Intratumoral & $\begin{array}{l}\text { Cyclophosphamide } \\
\text { pembrolizumab }\end{array}$ \\
\hline $\begin{array}{l}\text { OBP-301 } \\
\text { (Telomelysin) }\end{array}$ & Adenovirus & $\begin{array}{l}\text { Incorporates } h T E R T \text { to drive viral replication } \\
\text { genes } E 1 A \text { and } E 1 B^{[73,74]}\end{array}$ & $\begin{array}{l}\text { Oncolys } \\
\text { BioPharma }\end{array}$ & Intratumoral & $\begin{array}{l}\text { Monotherapy } \\
\text { pembrolizumab }\end{array}$ \\
\hline $\begin{array}{l}\text { HF10 (TBI-1401, } \\
\text { canerpaturev, C-REV) }\end{array}$ & HSV1 & $\begin{array}{l}\text { Loss of expression of UL43, U149.5, UL55, } \\
\text { UL56, and LAT; overexpression of UL53, } \\
\text { UL54 } 5468,75]\end{array}$ & Takara Bio & Intratumoral & $\begin{array}{l}\text { Monotherapy } \\
\text { Ipilimumab } \\
\text { Nivolumab }\end{array}$ \\
\hline ONCR-177 & HSV1 & $\begin{array}{l}\text { miRNA attenuation of ICP4, ICP27, UL8, } \\
\text { ICP34.5; Expresses IL12, FLT3LG, and CCL4 } \\
\text { transgenes, and anti-PD-1 and anti-CLTA-4 } \\
\text { IgG }\end{array}$ & Oncorus & Intratumoral & Pembrolizumab \\
\hline RP1 & HSV1 & $\begin{array}{l}\text { Deletion ICP34.5, ICP47; Expresses GALV- } \\
\text { GP R- and GM-CSF } 777,78]^{\prime}\end{array}$ & Replimune & Intratumoral & $\begin{array}{l}\text { Monotherapy } \\
\text { nivolumab }\end{array}$ \\
\hline $\mathrm{OH} 2$ & HSV2 & $\begin{array}{l}\text { Deletion ICP34.5, ICP47; expresses GM- } \\
\text { CSFF }^{[79,80]}\end{array}$ & $\begin{array}{l}\text { Wuhan binhui } \\
\text { biotechnology }\end{array}$ & Intratumoral & HX008 (anti-PD-1) \\
\hline
\end{tabular}

ICAM-1: Intercellular adhesion molecule-1; hCTLA-4: human Cytotoxic T-lymphocyte-associated protein 4; GM-CSF: granulocyte-macrophage colony-stimulating factor; TNF-alpha: tumor necrosis factor alpha; IL: interleukin; PD-L1: programmed death-ligand 1; hTERT: human telomerase reverse transcriptase; LAT: latency-associated transcripts; HSV: herpes simplex virus; FLT3LG: fms related receptor tyrosine kinase 3 ligand; CCL4: C-C motif ligands 4; TIL: tumor-infiltrating lymphocyte.

\section{T-VEC as neoadjuvant therapy:combination therapies}

There are several ongoing studies that are currently evaluating T-VEC in combination with other immunotherapies in the neoadjuvant setting, including nivolumab and pembrolizumab. A single-arm, open-label phase II trial is evaluating the efficacy of T-VEC plus nivolumab as neoadjuvant therapy for patients with resectable stage IIIB-IVM1a melanoma with a primary outcome of $\mathrm{pCR}^{[63]}$. The study is currently ongoing and recruiting patients. A single-arm, open-label phase II trial is evaluating the safety and efficacy of neoadjuvant therapy with T-VEC plus pembrolizumab in patients with resectable stage III melanoma with clinically positive lymph node involvement prior to undergoing lymph node dissection ${ }^{[64]}$. T-VEC will be injected intratumorally into palpable lymph nodes every 3 weeks over a 6 -month period or until the patient achieves CR. Pembrolizumab will be administered via IV every 3 months over a 6 -month period. Following lymph node dissection, adjuvant pembrolizumab was administered every 3 weeks for one year. The primary outcome measure of this study is $\mathrm{pCR}$, which will be assessed in the regional lymph nodes following surgical dissection. The study is currently ongoing and recruiting patients.

\section{OTHER OVS FOR MELANOMA THERAPY}

\section{Other OVs for melanoma therapy: overview}

There are a number of other OVs in development and under evaluation in clinical trials as monotherapy or in combination with systemic immunotherapies [Table 3]. As a general class, OVs follow the same principles as those outlined in the section "Mechanism of Action" above for T-VEC with variation in the 
virus used, the genes altered to limit pathogenicity, and genomic additions used to enhance immune response. The OV therapies likely vary in side effect profiles and may vary in efficacy, although no trials comparing OVs have been performed to date. See table for a list of additional OVs recently studied in clinical trials for melanoma. We believe additional OVs may eventually present other options for metastatic melanoma patients, but this needs to be evaluated in a rigorous fashion, just as T-VEC has been evaluated. We support continued clinical trial work to further elucidate the mechanism of action, side effect profile, and overall survival efficacy.

\section{CONCLUSIONS}

The management of cutaneous melanoma has undergone recent radical changes with the application of immunotherapy, targeted therapies, and T-VEC. These therapies have supplanted less effective and more morbid therapies and are changing the indications for established therapies such as surgery. Striking improvements in outcomes for patients with advanced disease are being realized. Further study is ongoing in predicting which patients respond to these therapies and whether patients with a poor response may be converted into responders using additional therapies. Further, outcomes will continue to improve as we enter the next generation of study in combining and/or sequencing therapies for advanced melanoma.

\section{DECLARATIONS}

\section{Authors' contributions}

Wrote the manuscript: Jenkins FG

Gave assistance: Johnson JE, Collichio F, Ollila DW

Supervised the project: Ollila DW

All authors contributed to the final manuscript.

\section{Availability of data and materials}

Not applicable.

\section{Financial support and sponsorship}

None.

\section{Conflicts of Interest}

Dr. Frances Collichio is the principle investigator at the University of North Carolina at Chapel Hill on clinical trials. Her institution receives funding from Amgen, Merck, Nektar Therapeutics, Replimune, and Novartis. A portion of her salary is derived from these funds. All other authors declared that there are no conflicts of interest.

\section{Ethical approval and consent to participate}

Not applicable.

\section{Consent for publication}

Not applicable.

\section{Copyright}

(C) The author(s) 2021

\section{REFERENCES}

1. Berk-Krauss J, Stein JA, Weber J, Polsky D, Geller AC. New systematic therapies and trends in cutaneous melanoma deaths among US whites, 1986-2016. Am J Public Health 2020;110:731-3. DOI PubMed PMC

2. National Cancer Institute. Drugs approved for melanoma. Available from: https://www.cancer.gov/aboutcancer/treatment/drugs/melanoma [Last accessed on 16 Aug 2021]. 
3. Louie RJ, Perez MC, Jajja MR, et al. Real-world outcomes of talimogene laherparepvec therapy: a multi-institutional experience. $J$ Am Coll Surg 2019;228:644-9. DOI PubMed

4. Pointer DT Jr, Zager JS. Management of locoregionally advanced melanoma. Surg Clin North Am 2020;100:109-25. DOI PubMed

5. Song X, Zhao Z, Barber B, Farr AM, Ivanov B, Novich M. Overall survival in patients with metastatic melanoma. Curr Med Res Opin 2015;31:987-91. DOI PubMed

6. National Cancer Institute. SEER cancer stat facts: melanoma of the skin. Available from: https://seer.cancer.gov/statfacts/html/melan.html [Last accessed on 16 Aug 2021].

7. National Cancer Institute. Melanoma of the skin: recent trends in SEER relative survival rates, 2000-2018. Available from: https://seer.cancer.gov/explorer/application.html [Last accessed on 16 Aug 2021].

8. National Comprehensive Cancer Network. Melanoma: cutaneous (Version 2.2021). Available from: https://www.nccn.org/professionals/physician_gls/pdf/cutaneous_melanoma.pdf [Last accessed on 16 Aug 2021].

9. Andtbacka RH, Kaufman HL, Collichio F, et al. Talimogene laherparepvec improves durable response rate in patients with advanced melanoma. J Clin Oncol 2015;33:2780-8. DOI PubMed

10. Ribas A, Dummer R, Puzanov I, et al. Oncolytic virotherapy promotes intratumoral T cell infiltration and improves Anti-PD-1 immunotherapy. Cell 2018;174:1031-2. DOI PubMed

11. Bommareddy PK, Aspromonte S, Zloza A, Rabkin SD, Kaufman HL. MEK inhibition enhances oncolytic virus immunotherapy through increased tumor cell killing and T cell activation. Sci Transl Med 2018;10:eaau0417. DOI PubMed PMC

12. Conry RM, Westbrook B, McKee S, Norwood TG. Talimogene laherparepvec: First in class oncolytic virotherapy. Hum Vaccin Immunother 2018;14:839-46. DOI PubMed PMC

13. Kohlhapp FJ, Kaufman HL. Molecular Pathways: Mechanism of action for talimogene laherparepvec, a new oncolytic virus immunotherapy. Clin Cancer Res 2016;22:1048-54. DOI PubMed

14. Liu BL, Robinson M, Han ZQ, et al. ICP34.5 deleted herpes simplex virus with enhanced oncolytic, immune stimulating, and antitumour properties. Gene Ther 2003;10:292-303. DOI PubMed

15. Mohr I, Sternberg D, Ward S, Leib D, Mulvey M, Gluzman Y. A herpes simplex virus type 1 gamma34.5 second-site suppressor mutant that exhibits enhanced growth in cultured glioblastoma cells is severely attenuated in animals. $J$ Virol 2001;75:5189-96. DOI PubMed PMC

16. Taneja S, MacGregor J, Markus S, Ha S, Mohr I. Enhanced antitumor efficacy of a herpes simplex virus mutant isolated by genetic selection in cancer cells. Proc Natl Acad Sci U S A 2001;98:8804-8. DOI PubMed PMC

17. Todo T, Martuza RL, Rabkin SD, Johnson PA. Oncolytic herpes simplex virus vector with enhanced MHC class I presentation and tumor cell killing. Proc Natl Acad Sci U S A 2001;98:6396-401. DOI PubMed PMC

18. He B, Chou J, Brandimarti R, Mohr I, Gluzman Y, Roizman B. Suppression of the phenotype of gamma(1)34.5- herpes simplex virus 1: failure of activated RNA-dependent protein kinase to shut off protein synthesis is associated with a deletion in the domain of the alpha47 gene. J Virol 1997;71:6049-54. DOI PubMed PMC

19. Mohr I, Gluzman Y. A herpesvirus genetic element which affects translation in the absence of the viral GADD34 function. Embo $j$ 1996;15:4759-66. PubMed PMC

20. Cassady KA, Gross M, Roizman B. The herpes simplex virus US11 protein effectively compensates for the gamma1(34.5) gene if present before activation of protein kinase $\mathrm{R}$ by precluding its phosphorylation and that of the alpha subunit of eukaryotic translation initiation factor 2. J Virol 1998;72:8620-6. DOI PubMed PMC

21. Toda M, Martuza RL, Rabkin SD. Tumor growth inhibition by intratumoral inoculation of defective herpes simplex virus vectors expressing granulocyte-macrophage colony-stimulating factor. Mol Ther 2000;2:324-9. DOI PubMed

22. Kaufman HL, Kim DW, DeRaffele G, Mitcham J, Coffin RS, Kim-Schulze S. Local and distant immunity induced by intralesional vaccination with an oncolytic herpes virus encoding GM-CSF in patients with stage IIIc and IV melanoma. Ann Surg Oncol 2010;17:718-30. DOI PubMed

23. Hu JC, Coffin RS, Davis CJ, et al. A phase I study of OncoVEXGM-CSF, a second-generation oncolytic herpes simplex virus expressing granulocyte macrophage colony-stimulating factor. Clin Cancer Res 2006;12:6737-47. DOI PubMed

24. Harrington KJ, Hingorani M, Tanay MA, et al. Phase I/II study of oncolytic HSV GM-CSF in combination with radiotherapy and cisplatin in untreated stage III/IV squamous cell cancer of the head and neck. Clin Cancer Res 2010;16:4005-15. DOI PubMed

25. Senzer NN, Kaufman HL, Amatruda T, et al. Phase II clinical trial of a granulocyte-macrophage colony-stimulating factor-encoding, second-generation oncolytic herpesvirus in patients with unresectable metastatic melanoma. J Clin Oncol 2009;27:5763-71. DOI PubMed

26. Andtbacka RHI, Amatruda T, Nemunaitis J, et al. Biodistribution, shedding, and transmissibility of the oncolytic virus talimogene laherparepvec in patients with melanoma. EBioMedicine 2019;47:89-97. DOI PubMed PMC

27. Collichio F, Burke L, Proctor A, et al. Implementing a program of talimogene laherparepvec. Ann Surg Oncol 2018;25:1828-35. DOI PubMed

28. Burke LMB, Yu H, Burke K, et al. Ultrasound-guided intralesional injection of talimogene laherparepvec (imlygic) for advanced melanoma: technical note on a preliminary experience. Cardiovasc Intervent Radiol 2021;44:801-6. DOI PubMed

29. Andtbacka RHI, Collichio F, Harrington KJ, et al. Final analyses of OPTiM: a randomized phase III trial of talimogene laherparepvec versus granulocyte-macrophage colony-stimulating factor in unresectable stage III-IV melanoma. J Immunother Cancer 2019;7:145. DOI PubMed PMC

30. Andtbacka RH, Ross M, Puzanov I, et al. Patterns of clinical response with talimogene laherparepvec (T-VEC) in patients with melanoma treated in the OPTiM phase III clinical trial. Ann Surg Oncol 2016;23:4169-77. DOI PubMed PMC 
31. U.S. Food and Drug Administration. IMLYGIC (talimogene laherparepvec). Available from: https://www.fda.gov/vaccines-bloodbiologics/cellular-gene-therapy-products/imlygic-talimogene-laherparepvec [Last accessed on 16 Aug 2021].

32. U.S. National Institutes of Health. Postmarketing prospective study of melanoma patients treated with IMLYGIC® to characterize risk of herpetic infection. Available from: https://clinicaltrials.gov/ct2/show/NCT02910557 [Last accessed on 16 Aug 2021].

33. Health USNIo. A registry study to evaluate the survival and long-term safety of subjects who previously received talimogene laherparepvec in Amgen or BioVEX-sponsored clinical trials. Available from: https://clinicaltrials.gov/ct2/show/NCT02173171 [Last accessed on 16 Aug 2021].

34. Puzanov I, Milhem MM, Minor D, et al. Talimogene laherparepvec in combination with ipilimumab in previously untreated, unresectable stage IIIB-IV melanoma. J Clin Oncol 2016;34:2619-26. DOI PubMed PMC

35. Chesney J, Puzanov I, Collichio F, et al. Randomized, open-label phase II study evaluating the efficacy and safety of talimogene laherparepvec in combination with ipilimumab versus ipilimumab alone in patients with advanced, unresectable melanoma. $J$ Clin Oncol 2018;36:1658-67. DOI PubMed PMC

36. Puzanov I, Chesney J, Collichio F, et al. 433 Talimogene laherparepvec (T-VEC) in combination with ipilimumab (IPI) versus IPI alone for advanced melanoma: 4-year interim analysis of a randomized, open-label, phase 2 trial. J Immunother Cancer 2020;8:A459A459. DOI

37. Chesney J, Puzanov I, Collichio F, et al. Patterns of response with talimogene laherparepvec in combination with ipilimumab or ipilimumab alone in metastatic unresectable melanoma. Br J Cancer 2019;121:417-20. DOI PubMed PMC

38. Moesta AK, Cooke K, Piasecki J, et al. Local delivery of OncoVEX ${ }^{\mathrm{mGM}-\mathrm{CSF}}$ generates systemic antitumor immune responses enhanced by cytotoxic T-lymphocyte-associated protein blockade. Clin Cancer Res 2017;23:6190-202. DOI PubMed

39. Long G, Dummer R, Johnson D, et al. 429 Long-term analysis of MASTERKEY-265 phase 1b trial of talimogene laherparepvec (TVEC) plus pembrolizumab in patients with unresectable stage IIIB-IVM1c melanoma. J Immunother Cancer 2020;8:A454. DOI

40. U.S. National Institutes of Health. Pembrolizumab with or without talimogene laherparepvec or talimogene laherparepvec placebo in unresected melanoma (KEYNOTE-034). Available from: https://clinicaltrials.gov/ct2/show/NCT02263508 [Last accessed on 16 Aug 2021].

41. U.S. National Institutes of Health. Talimogene laherparepvec and pembrolizumab in treating patients with stage III-IV melanoma. Available from: https://clinicaltrials.gov/ct2/show/NCT02965716 [Last accessed on 16 Aug 2021].

42. U.S. National Institutes of Health. Talimogene laherparepvec with pembrolizumab in melanoma following progression on prior AntiPD-1 based therapy (MASTERKEY-115) (Mk-3475-A07/KEYNOTE-A07). Available from: https://clinicaltrials.gov/ct2/show/NCT04068181 [Last accessed on 16 Aug 2021].

43. U.S. National Institutes of Health. Trial to evaluate the safety of talimogene laherparepvec injected into tumors alone and in combination with systemic pembrolizumab MK-3475-611/Keynote-611 (MASTERKEY-318). Available from: https://clinicaltrials.gov/ct2/show/NCT02509507 [Last accessed on 16 Aug 2021].

44. Sun L, Funchain P, Song JM, et al. Talimogene laherparepvec combined with anti-PD-1 based immunotherapy for unresectable stage III-IV melanoma: a case series. J Immunother Cancer 2018;6:36. DOI PubMed PMC

45. Behera TR, Song JM, Ko JS, Mcnamara MJ, Funchain P, Gastman B. Real-world experience of talimogene laherparepvec in patients receiving immunotherapy in metastatic melanoma. J Clin Oncol 2020;38:e22003. DOI

46. Long GV, Stroyakovskiy D, Gogas H, et al. Combined BRAF and MEK inhibition versus BRAF inhibition alone in melanoma. $N$ Engl J Med 2014;371:1877-88. DOI PubMed

47. Kakadia S, Yarlagadda N, Awad R, et al. Mechanisms of resistance to BRAF and MEK inhibitors and clinical update of US Food and Drug Administration-approved targeted therapy in advanced melanoma. Onco Targets Ther 2018;11:7095-107. DOI PubMed PMC

48. Gholami S, Chen CH, Gao S, et al. Role of MAPK in oncolytic herpes viral therapy in triple-negative breast cancer. Cancer Gene Ther 2014;21:283-9. DOI PubMed

49. U.S. National Institutes of Health. Combining talimogene laherparepvec with BRAF and MEK inhibitors in BRAF mutated advanced melanoma. Available from: https://clinicaltrials.gov/ct2/show/NCT03088176 [Last accessed on 16 Aug 2021].

50. U.S. National Institutes of Health. Intratumoral injection of autologous CD1c (BDCA-1)+ myeloid dendritic cells plus talimogene laherparepvec (T-VEC) (myDCTV). Available from: https:/clinicaltrials.gov/ct2/show/NCT03747744 [Last accessed on 16 Aug 2021].

51. Broz ML, Binnewies M, Boldajipour B, et al. Dissecting the tumor myeloid compartment reveals rare activating antigen-presenting cells critical for T cell immunity. Cancer Cell 2014;26:638-52. DOI PubMed PMC

52. Roberts EW, Broz ML, Binnewies M, et al. Critical role for CD103(+)/CD141(+) dendritic cells bearing CCR7 for tumor antigen trafficking and priming of $t$ cell immunity in melanoma. Cancer Cell 2016;30:324-36. DOI PubMed PMC

53. U.S. National Institutes of Health. TITAN (Tumoural Injection of T-VEC and Isolated Limb Perfusion) (TITAN). Available from: https://clinicaltrials.gov/ct2/show/NCT03555032 [Last accessed on 16 Aug 2021].

54. U.S. National Institutes of Health. A Study of T-VEC (Talimogene Laherparepvec) With or without radiotherapy for melanoma, merkel cell carcinoma, or other solid tumors. Available from: https://clinicaltrials.gov/ct2/show/NCT02819843 [Last accessed on 16 Aug 2021].

55. Kelly ZR, Gorantla VC, Davar D. The role of neoadjuvant therapy in melanoma. Curr Oncol Rep 2020;22:80. DOI PubMed

56. Pelster MS, Amaria RN. Neoadjuvant Immunotherapy for Locally Advanced Melanoma. Curr Treat Options Oncol 2020;21:10. DOI PubMed

57. U.S. National Institutes of Health. Neoadjuvant T-VEC in high risk early melanoma. Available from: https://clinicaltrials.gov/ct2/show/NCT04427306 [Last accessed on 16 Aug 2021]. 
58. U.S. National Institutes of Health. Efficacy and safety of talimogene laherparepvec neoadjuvant treatment plus surgery versus surgery alone for melanoma. Available from: https://clinicaltrials.gov/ct2/show/NCT02211131 [Last accessed on 16 Aug 2021].

59. Andtbacka RHI, Dummer R, Gyorki DE, et al. Interim analysis of a randomized, open-label phase 2 study of talimogene laherparepvec (T-VEC) neoadjuvant treatment (neotx) plus surgery (surgx) vs surgx for resectable stage IIIB-IVM1a melanoma (MEL). J Clin Oncol 2018;36:9508. DOI

60. Dummer R, Gyorki DE, Hyngstrom JR, et al. One-year (yr) recurrence-free survival (RFS) from a randomized, open label phase II study of neoadjuvant (neo) talimogene laherparepvec (T-VEC) plus surgery (surgx) versus surgx for resectable stage IIIB-IVM1a melanoma (MEL). J Clin Oncol 2019;37:9520. DOI

61. Dummer R, Gyorki D, Hyngstrom J, et al. Primary 2-year (yr) results of a phase II, multicenter, randomized, open-label trial of efficacy and safety for talimogene laherparepvec (T-VEC) neoadjuvant (neo) treatment (tx) plus surgery (surg) vs surg in patients (pts) with resectable stage IIIB-IVM1a melanoma. Ann Oncol 2019;30:v903. DOI

62. Dummer R, Gyorki D, Hyngstrom J, et al. 432 3-year results of the phase 2 randomized trial for talimogene laherparepvec (T-VEC) neoadjuvant treatment plus surgery vs surgery in patients with resectable stage IIIB-IVM1a melanoma. $J$ Immunother Cancer 2020;8:A458. DOI

63. U.S. National Institutes of Health. Neo-adjuvant T-VEC + nivolumab combination therapy for resectable early metastatic (Stage IIIB/C/D-IV M1a) melanoma with injectable disease (NIVEC). Available from: https://clinicaltrials.gov/ct2/show/NCT04330430 [Last accessed on 16 Aug 2021].

64. U.S. National Institutes of Health. Neoadjuvant combination immunotherapy for stage III melanoma. Available from: https://clinicaltrials.gov/ct2/show/NCT03842943 [Last accessed on 16 Aug 2021].

65. U.S. National Institutes of Health. Ipilimumab with or without talimogene laherparepvec in unresected melanoma. Available from: https://clinicaltrials.gov/ct2/show/NCT01740297 [Last accessed on 16 Aug 2021].

66. Bradley S, Jakes AD, Harrington K, Pandha H, Melcher A, Errington-Mais F. Applications of coxsackievirus A21 in oncology. Oncolytic Virother 2014;3:47-55. DOI PubMed PMC

67. Hamid O, Ismail R, Puzanov I. Intratumoral immunotherapy-update 2019. Oncologist 2020;25:e423-38. DOI PubMed PMC

68. Eissa IR, Bustos-Villalobos I, Ichinose T, et al. The current status and future prospects of oncolytic viruses in clinical trials against melanoma, glioma, pancreatic, and breast cancers. Cancers (Basel) 2018;10:356. DOI PubMed PMC

69. U.S. National Institutes of Health. A clinical trial assessing BT-001 alone and in combination with pembrolizumab in metastatic or advanced solid tumors. Available from: https://clinicaltrials.gov/ct2/show/NCT04725331 [Last accessed on 16 Aug 2021].

70. Havunen R, Kalliokoski R, Siurala M, et al. Cytokine-coding oncolytic adenovirus TILT-123 is safe, selective, and effective as a single agent and in combination with immune checkpoint inhibitor Anti-PD-1. Cells 2021;10:246. DOI PubMed PMC

71. U.S. National Institutes of Health. A pilot study of sequential ONCOS-102, an engineered oncolytic adenovirus expressing GMCSF, and pembrolizumab in patients with advanced or unresectable melanoma progressing after programmed cell death protein 1 (PD1) blockade. Available from: https://clinicaltrials.gov/ct2/show/NCT03003676 [Last accessed on 16 Aug 2021].

72. Kuryk L, Møller AW, Jaderberg M. Combination of immunogenic oncolytic adenovirus ONCOS-102 with anti-PD-1 pembrolizumab exhibits synergistic antitumor effect in humanized A2058 melanoma huNOG mouse model. Oncoimmunology 2019;8:e1532763. DOI PubMed PMC

73. Kyo S, Takakura M, Fujiwara T, Inoue M. Understanding and exploiting hTERT promoter regulation for diagnosis and treatment of human cancers. Cancer Sci 2008;99:1528-38. DOI PubMed

74. U.S. National Institutes of Health. Evaluate efficacy, immunological response of intratumoral/intralesional oncolytic virus (OBP-301) in metastatic melanoma. Available from: https://clinicaltrials.gov/ct2/show/NCT03190824 [Last accessed on 16 Aug 2021].

75. Eissa IR, Naoe Y, Bustos-Villalobos I, et al. Genomic signature of the natural oncolytic herpes simplex virus HF10 and its therapeutic role in preclinical and clinical trials. Front Oncol 2017;7:149. DOI PubMed PMC

76. Haines BB, Denslow A, Grzesik P, et al. ONCR-177, an Oncolytic HSV-1 designed to potently activate systemic antitumor immunity. Cancer Immunol Res 2021;9:291-308. DOI PubMed

77. Thomas S, Kuncheria L, Roulstone V, et al. Development of a new fusion-enhanced oncolytic immunotherapy platform based on herpes simplex virus type 1. J Immunother Cancer 2019;7:214. DOI PubMed PMC

78. Middleton MR, Aroldi F, Sacco J, et al. An open-label, single-arm, phase II clinical trial of RP1, an enhanced potency oncolytic herpes virus, combined with nivolumab in four solid tumor types: initial results from the skin cancer cohorts. J Clin Oncol 2020;38:e22050. DOI

79. U.S. National Institutes of Health. OH2 Injection in Combination With HX008 for Melanoma. Available from: https://clinicaltrials.gov/ct2/show/NCT04616443 [Last accessed on 16 Aug 2021].

80. Zhao Q, Zhang W, Ning Z, et al. A novel oncolytic herpes simplex virus type 2 has potent anti-tumor activity. PLoS One 2014;9:e93103. DOI PubMed PMC 